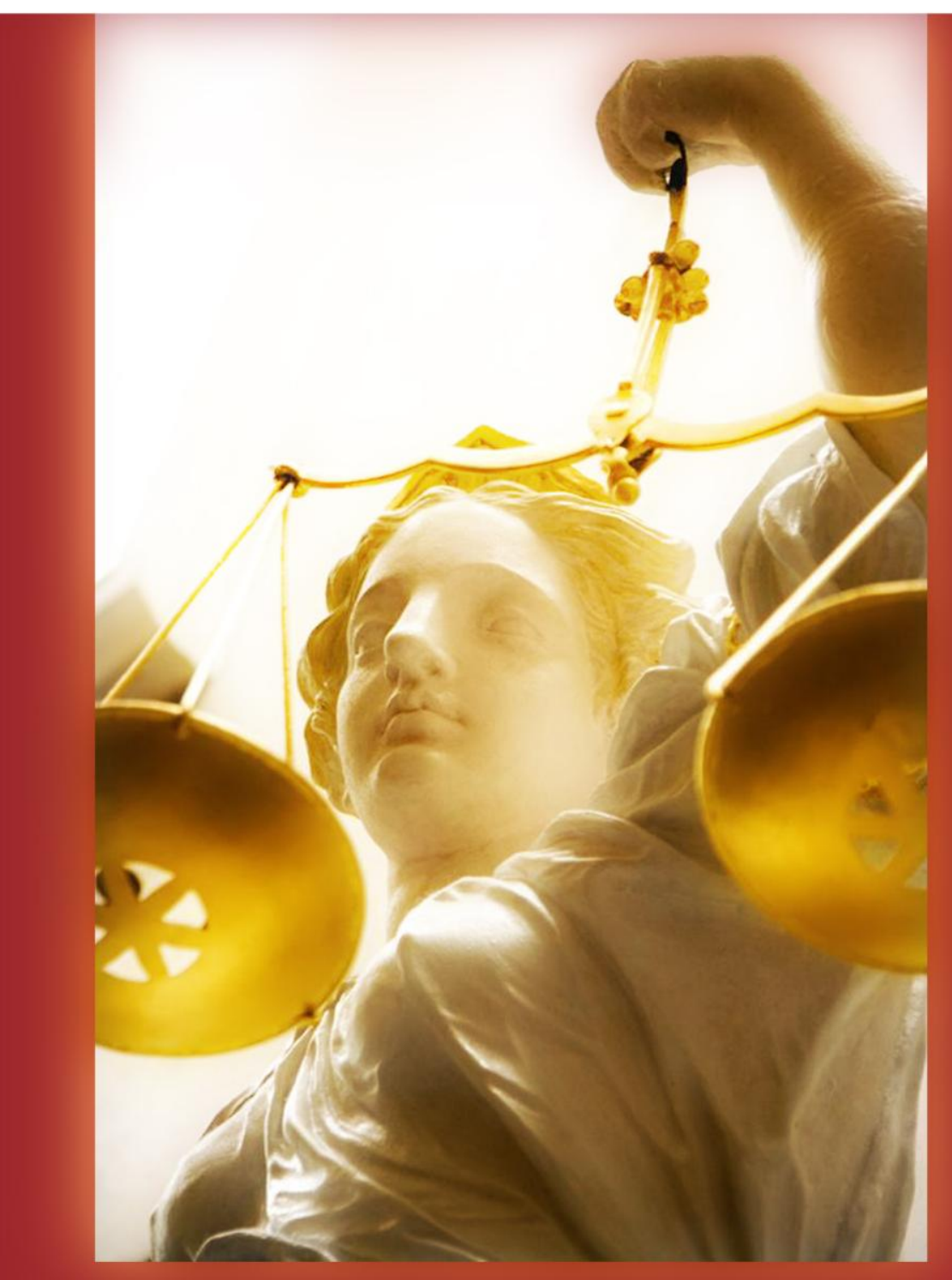

Mental Illness, Law, and a Public Health Law

Research Agenda

\author{
John Petrila, J.D., LL.M. \\ Jeffrey Swanson, Ph.D.
}

Public Health Law Research

Making the Case for Laws That Improve Health 


\title{
Mental Illness, Law, and a Public Health Law Research Agenda
}

\section{December 2010}

\author{
A Theory, Practice, Evidence Monograph \\ for the \\ Public Health Law Research Program (PHLR) \\ Temple University Beasley School of Law
}

\author{
Authors: \\ John Petrila, JD, LLM \\ Professor, Department of Mental Health Law \& Policy, \\ Louis de la Parte Florida Mental Health Institute \\ College of Behavioral and Community Sciences, College of Public Health \\ University of South Florida \\ Jeffrey Swanson, Ph.D. \\ Professor, Department of Psychiatry \& Behavioral Sciences \\ Duke University School of Medicine
}




\section{Introduction}

The prevention and treatment of mental illnesses are part of public health. The relationship between mental health and physical health is undeniable. Mental disorders involve neurobiological pathologies that may be linked to social-environmental as well as heritable risk factors; can increase the risk for communicable and non-communicable diseases; and play a significant role in intentional and unintentional injury. In turn, many health conditions can increase the risk for mental illness (Prince, Patel, Saxena, Maj, Maselko, Phillips, \& Rahman, 2007; Eaton, Martins, Nestadt, Bienvenu, Clarke, \& Alexandre, 2008). The costs of mental disorders go beyond disease. They are associated with poverty, marginalization, and social disadvantage, and people suffering from mental disorders often face stigma and discrimination (World Health Organization, 2008).

While "mental illness contributes a substantial burden of disease worldwide" (Williams, Chapman, \& Lando, 2005), it is only recently that its place in public health has been widely recognized. There are myriad reasons for this, including longstanding stigma associated with mental illnesses (Sartorius, 2007), public fear of the "violent mentally ill", inadequate investments in treatment, a treatment system that in the United States relied historically on confining large numbers of patients in state institutions isolated from their communities, and entrenched doubts about whether mental illnesses were "real diseases" at all. In the last decade, however, numerous policymakers have concluded that the integration of mental health within public health is essential to improving care for people with or at risk for mental illnesses (DHHS, 1999; The President's New Freedom Commission on Mental Health, 2003; Institute of Medicine, 2006; World Health Organization, 2008). Today, few question whether mental health is part of 
public health or whether mental illnesses are actually illnesses, though access to care and the availability of adequate services capacity are global issues (World Health Organization, 2008).

Law has played a significant and varied role in shaping mental health policy and practice in the United States since the late 1960s. Constitutional principles have been used to challenge conditions of institutional confinement and the processes by which people are involuntarily confined. State and federal legislation has attempted to provide parity in insurance coverage for physical and mental illnesses, and to reduce the impact of both physical and mental disabilities on access to employment and public accommodations. Conversely, state and federal laws also have expanded the use of coercion and denied people with mental illnesses access to products (such as guns) otherwise available to most citizens. In each example, the law has been used in an effort to enhance health outcomes and/or reduce the public risk presumed to emerge from untreated mental illnesses.

"Mental health law" is frequently used as a catchall for the variety of cases, statutes, and administrative decisions that have an impact on people with mental illnesses. Given that mental health has often been an afterthought in discussions of public health, it is not surprising that many consider "mental health law" to be separate from, rather than part of public health law. However, the legal strands that make up this purported body of law are only occasionally applied uniquely to people with mental illnesses and are usually rooted in legal principles applied to general public health issues.

Through the 1970s, mental health policy and law affecting people with mental illnesses existed largely in an empirical vacuum. Over the last three decades, research has begun to fill this empirical void and illuminate the law's impact on questions of access to care, decisional 
capacity, the relationship between violence and mental illness, and the use of coercion in community settings. However, many questions about the impact of law on the population affected by, or at risk for, mental illnesses warrant new or continuing inquiry. Some of these researchable questions focus on the effectiveness of the state's use of legal and regulatory authority and infrastructure to achieve certain broad public health goals, such as reducing community violence, by limiting the freedom of certain people with mental illness who are purportedly at increased risk of violence. Other questions involve the impact of legal interventions to shape the behavior of people with serious mental illnesses in order to improve their access to needed care, with the goal of reducing and preventing psychiatric morbidity and disability in this population. Still other research questions involve the impact of laws with broad reach that incidentally affect people with mental illnesses, such as the Americans with Disabilities Act. In attempting to discern the relationship of law and mental health/illness at the population level, research addressing these and similar questions fall squarely within a public health law research framework.

The remainder of this paper places "mental health law" and the research into the law's impact on people with mental illness within the larger context of public health law and public health law research. The paper has three sections. The first describes the overarching legal principles that have been applied to people with mental illnesses (principles used in other public health contexts as well), first in an era in which state institutions were the primary venue for care and then in the current environment, where community care dominates. The second section describes the state of research on the relationship between law and the population with a mental illness. The third section establishes a framework for future research, and provides examples of 
the types of public health law research studies that could focus on the impact of law on population mental health.

\section{Part 1. Law, mental illness and public health}

Gostin defines public health law as "the study of the legal powers and duties of the state to ensure the conditions for people to be healthy (e.g., to identify, prevent, and ameliorate risks to health and safety in the population), and the limitations on the power of the state to constrain the autonomy, privacy, liberty, proprietary, or other legally protected interests of individuals for protection or promotion of community health" (Gostin, 2000; Gostin, 2008). This "power/duty/restraint" framework also nicely frames issues at the core of the application of law to people with mental illnesses. These issues include the reach of state power to coerce people into care; the duty of states to provide care; efforts to assure voluntary access to care; and the use of law to protect individuals and the public from dangerousness. Keeping Gostin's formulation in mind, we organize this discussion under the three broad domains utilized by Burris and colleagues in their proposed framework for public health law research (Burris, Wagenaar, Swanson, et al, 2010). These domains include infrastructural law (establishing the powers, duties, and institutions of public health), interventional law (law or legal practices that are intended to influence health outcomes or mediators directly) and incidental law (law and legal practices that may have a relationship to population health, whether the law or legal practice is health-oriented on its face; in this paper, we broaden the definition to include laws that have an 
impact on people with mental illnesses but that were adopted with a broader population in mind). ${ }^{1}$

\section{Infrastructural law: The use and restraint of state coercive authority, and state} duties to provide care in institutional and community settings.

Two perennial issues in law and mental health are the reach of and limits on the use of the state's coercive power, and whether government has an obligation to provide care. Both have to do with population health either through providing protection from harm or through making treatment available (which in turn theoretically may reduce harm).

These issues initially assumed prominence because of the state's role as the primary provider of care to people with serious mental illnesses and because state statutes permit the use of coercion to place people in state institutions. Initially the courts constrained the use of the state's coercive power and imposed duties on the state in its role as service provider. However the courts lately have revitalized the state's coercive powers in the interest of identifying and ameliorating perceived risks to the public, while limiting the state's duties in the context of community care.

\footnotetext{
${ }^{1}$ These broad domains provide a useful heuristic for discussing law and research, but there are no hard and fast rules regarding the placement of specific legal rules (or research) within a particular domain. For example, we discuss outpatient commitment within the domain of infrastructural law, because outpatient commitment statutes establish the powers of the state to use coercion in attempting to cause an individual to accept treatment. However, one could place it in a discussion of interventional law, since judges use outpatient commitment orders as an intervention strategy in specific cases. Similarly, we discuss conditioning housing on adherence to treatment as part of interventional law, because in the context of people with mental illnesses it is often used as an intervention. However, housing could be discussed in this context as incidental law, because public housing laws are not designed to accomplish therapeutic aims, but using housing as leverage may incidentally accomplish such aims.
} 
The development and application of legal doctrine to mental health on these and other issues has rested in part on social constructs of mental illness, as well as assumptions about the relationship between mental illness and violence. Perceptions of the etiology of mental illness have varied by culture and over time (Millon, 2004). The tension between rationalist explanations and explanations based on public fear goes back at least to Plato's time (Seeskin, 2008). While consensus on the etiology of mental illnesses has been difficult to achieve, people in nearly all cultures have assumed that violence and mental illness are related (Monahan, 1992). The belief that people with mental illnesses are disproportionately violent has long been a linchpin for public policy arguments regarding the provision and conditions of care. In colonial America, Benjamin Franklin urged the Pennsylvania Assembly to create a special ward for the treatment of mental illness, by asserting

The Number of Persons distempered in Mind and deprived of their rational Faculties has increased greatly in this province. Some of them going at large are a terror to their Neighbors, who are daily apprehensive of the Violences they may commit (cited in Deutsch, 1949, p. 59).

The assumed relationship between mental illness and violence was and continues to be used to justify specialized treatment and confinement for people with mental illnesses. However, the policy of using separate asylums to treat mental illness rested initially on the benevolent philosophy of "moral treatment" which posited that "insanity" could best be treated in small asylums in pastoral settings, using good hygiene and diet, occupational activities, medical care, and religious practice (Tuke, 2009/1813). By the middle of the 20th century, this ideal had given way to the emergence of a very different kind of institution. The census of state hospitals had 
exploded, and in 1955, state psychiatric hospitals housed 558,922 individuals in a nation of 166 million people (Appelbaum, 1994). Some of these institutions were virtual cities. For example, Pilgrim Psychiatric Center, the largest, housed 13,875 patients at its peak. As these institutions grew in size, many became unsafe, understaffed, and overcrowded. Overdrugging was routine, with dangerous side effects to patients. Many people were institutionalized through involuntary civil commitment, and people could spend decades in confinement, lost to the outside world.

In the first widespread use of law on behalf of people with mental illnesses, civil rights lawyers in the 1960s began challenging both the medically-oriented civil commitment statutes that provided a gate to confinement and the often dangerous conditions in which people were confined. Using Gostin's public health law formulation, lawsuits challenging the constitutionality of involuntary commitment laws sought to restrain the State's power to use coercion as a vehicle to force people into psychiatric care; lawsuits challenging the conditions of the institutions into which people were coerced sought to expand the State's duty to keep people in its custody safe and to provide them with treatment.

There was little doubt about the state's legal authority to confine people based on dangerousness; indeed, courts had routinely rejected challenges to the state's power to confine individuals with other diseases, such as tuberculosis, that endangered the public (see, e.g., Moore v. Draper, 1952, in which the Florida Supreme Court rejected a habeas corpus petition by an involuntarily confined tuberculosis patient arguing that his constitutional rights were violated by his confinement). Legal challenges to state commitment laws focused more closely on the arguably unchecked use of the state's parens patriae power, to ends that were demonstrably nontherapeutic. Faced with this litigation, federal courts repeatedly found that states were violating

Mental Illness, Law, and a Public Health Law Research Agenda 
constitutional rights to liberty and due process. As remedies, courts directed states to revise their civil commitment laws to provide procedural protections more commonly associated with criminal process, and to incorporate dangerousness to self or others as a necessary substantive criterion for commitment (Lessard v. Schmidt, 1971, is the seminal case on this issue). Courts also ordered states to improve conditions in state institutions and in some cases assumed control over the administration of those facilities, just as courts were ordering similar reforms in other state and local correctional and juvenile justice facilities and in facilities for people who had development disabilities. In response, most states rewrote their civil commitment laws to meet emerging constitutional norms. As a result a statutory framework anchored in the notion that civil commitment deprived constitutionally protected liberty became the new norm. States also moved to improve conditions in state institutions, sometimes discharging patients to reduce census and thereby comply with court ordered staff-patient ratios (Weisbrod, Handler, \& Komesar, 1978).

The forced segregation of groups of people identified by a particular class of illness was and is not restricted to people with mental illnesses. While state psychiatric institutions were growing to unmanageable size, thousands of people with tuberculosis were being confined in sanitaria to protect the public. Many died in those institutions. Some courts that have more recently considered application of the state's coercive power to confinement of people with tuberculosis have drawn analogies between tuberculosis and mental illness (City of Newark $v$. J.S., (1993) and looked to state civil commitment statutes for purposes of comparison. However, while segregated care and legal challenges to it extend to more diseases than mental illnesses, Some scholars have pointed out that one can press the analogy between mental illnesses and other diseases too far. He notes that decisions about whether a person with mental illness is a 
danger to self or others are inherently subjective, with the term of commitment open-ended. In contrast, quarantine orders rest on diseases that can be objectively diagnosed with certain risk factors, and result in confinement that automatically ends at the end of incubation or successful treatment (Richards, Burris, McNelis, \& Hargan, 2005).

While all would agree that tuberculosis is a disease, the assumption that mental illness was not a disease, but rather a pernicious social construct, originally animated the lawyers bringing early cases against state mental health systems. Thomas Szasz, a psychiatrist, was particularly influential in this regard, writing that "mental illness is a metaphor...As the whale is not a fish, mental illness is not a disease... The classification of (mis)behavior as an illness provides an ideological justification for state sponsored social control as medical treatment" (Szasz, 1998). The construct of mental illness as a tool of social control resulted in litigation designed not to create access to care but rather to create barriers to contact between individuals with mental illnesses and caregivers, based on the belief that institutional care (the primary venue for mental health treatment through the early 1980s) was intrinsically harmful. This, combined with judicially imposed limits on the reach of constitutionally derived remedies, meant that little attention was paid to what happened to people after they left an institution, or when they were not admitted to care at all. As a result, this litigation, described elsewhere as "almost a revolution" (Appelbaum, 1994) ignored significant facets of the health of the population it was designed to assist.

\section{Community mental health and access to care: Expansion of state authority based on perceived risk and limits on state duty.}


Judicial rulings constraining the state's use of coercion and directing states to improve institutional conditions were one of many factors that contributed to the continuous depopulation of state hospitals from the mid-1950s forward. New psychotropic medications, changes in financing rules that permitted reimbursement for various types of community care, and changing treatment philosophies also were important drivers of deinstitutionalization (Gelman, 1997; Mechanic \& Rochefort, 1990). The decline in state hospital census over 50 years was dramatic. In 2003, even with the rate of deinstitutionalization slowing (Salzter, Kaplan, \& Atay, 2006), state hospitals held fewer than 50,000 people - down from over a half million in the mid-1950s (Manderscheid, Atay, \& Crider, 2009).

While deinstitutionalization became the centerpiece of mental health policy, it was almost immediately judged a failure, largely because of inadequate community treatment resources (General Accounting Office, 1977; President's Commission on Mental Health, 1978). Over time, advocates for people with mental illnesses brought lawsuits designed to create legal entitlements to community care and housing, a focus on access and service capacity missing from earlier litigation. However, with one notable exception (Arnold v. Arizona Department of Health and Human Services, 1989, in which the Arizona Supreme Court directed Arizona to create a community care system for people with serious mental illnesses in Maricopa County) those efforts were largely unsuccessful, as courts ruled that neither federal nor state law mandated states to create treatment services or housing (Klapper, 1993).

Outpatient civil commitment. The 1960s-era sociological critiques of the "myth of mental illness" and of the conditions of the "asylum" had significant influence on mental health policy and law. Yet these critiques failed to animate the public will for an extensive community care system, which was needed, as it turned out, to replace the hospitals and, with or without 
coercion, to provide minimally adequate and continuing care for people with severe, chronic, and disabling psychiatric disorders.

To be clear, one did not have to think mental illness was a "myth" to be in favor of deinstitutionalization in the 1960s and 1970s. Major advances in pharmacotherapies, it seemed, were "just around the corner" and promised to alleviate, if not cure completely, the symptoms of mood and thought disorder — and this without the intolerable side effects that had made patients so loathe to take psychotropic medications and thus rendered coercion necessary. Moreover, clinical thinking about the treatment of serious mental illness had changed; the late Victorian ideal of mental respite in the asylum's pastoral setting had given way to a new therapeutic concept of recovery in the community that assumed that contact with family and friends and the trappings of a "normal life" was almost inherently salubrious, and indeed that this was needed as the antidote to the socially toxic influences of confinement in a massive mental hospital.

What happened instead was that the new medicines proved less than magical; life in the community failed to cure schizophrenia; and President Reagan effectively defunded the community mental health centers that had been initiated by President Kennedy's administration. People with serious, disabling psychiatric conditions emerged as an increasingly visible element in every urban community in the U.S. They "revolved" in and out of acute psychiatric hospitals, were chronically unemployed, sometimes homeless, and not infrequently came to the attention of the police and the criminal justice system. Some of them failed to recognize their need for treatment. Others sought treatment that was increasingly difficult to access. And still others received treatment that did not work. 
As the courts rejected efforts to extend constitutional guarantees to certain levels of care from the institution to the community, homelessness increased dramatically in urban centers across the United States. Two widespread assumptions about homelessness led to important consequences for mental health policy and law. First, many policy makers assumed that deinstitutionalization caused homelessness and thus concluded that most people who were homeless were also mentally ill. Second, based on the first assumption, many believed that the increase in homelessness necessarily would result in an increase in random acts of violence against the public and the degradation of urban environments. Some argued that expanding the reach of civil commitment laws to community settings to protect the public from the perceived dangerousness of people with untreated mental illnesses was an appropriate policy response (Torrey, 1997; Torrey \& Zdanowicz, 2001). Others argued for outpatient commitment from a clinical perspective as an appropriate remedy for the "revolving door syndrome" - a way to overcome, with a single court order, both the nonadherence of patients who lacked insight into their own best interest and the inattentiveness of an overburdened community care system that lacked the resources to serve them. If it was the law, it seemed, on both sides "they would have to do it."

While neither federal constitutional nor state statutory law were good tools for creating systems of care for people with serious illnesses, or for assuring voluntary access to services, changing social and judicial attitudes made them vehicles for expanding state authority to exercise coercion. Nearly all states adopted a version of outpatient civil commitment from the 1980s forward. While outpatient commitment statutes vary, they all permit courts to order certain people who are diagnosed with mental illness and reside in the community to comply with court imposed treatment conditions. Statutorily specified findings are necessary before a 
person can be committed to outpatient care. For example, many statutes require that the person be unwilling to seek treatment voluntarily, that the person have a history of "failed" treatment, and that resources are available to provide the necessary treatment. If the person fails to adhere to treatment, he or she may be removed to an inpatient facility for further assessment.

Courts have ruled that these statutes meet federal and state constitutional requirements. Such decisions are striking because they endorse a shift in the legal framework for civil commitment back in the direction of more medically oriented criteria. The New York Court of Appeals in In re K.L. (2004) explicitly endorsed state intervention to guard against prospective relapse, writing:

The state's interest in immediately removing from the streets noncompliant patients previously found to be, as a result of their noncompliance, at risk of a relapse or deterioration likely to result in serious harm to themselves or others is quite strong. The state has a further interest in warding off the longer periods of hospitalization that, as the Legislature has found, tend to accompany relapse or deterioration. ( $\mathrm{pp} \mathrm{487).}$

Judicial endorsement of expanded state authority to act coercively in the context of mental illness can also be understood in a broader context in which courts have upheld the state's authority to indefinitely confine sexual offenders at the expiration of their prison terms (Petrila, 2008), debates regarding government's authority in the "war on terror" (Cole, 2009), and discussions regarding the forcible confinement of people with new types of tuberculosis. In fact, in upholding a Kansas statute permitting the indefinite civil commitment of people identified as sexually violent predators, the United States Supreme Court drew an explicit analogy between civil commitment and the use of quarantine, writing

"We have never held that the Constitution prevents a State from civilly detaining those for whom no treatment is available, but who nevertheless pose a danger to others. A State 
could hardly be seen as furthering a 'punitive' purpose by involuntarily confining persons afflicted with an untreatable, highly contagious disease." (Kansas v. Hendricks, 1997). Indeed, with the emergence of a new drug-resistant strain of tuberculosis commentators have raised concerns over the potential use of compulsory treatment in the public health system, as well as inequalities in access to care (Gostin, 1995; Lyon \& Farmer, 2005). These concerns are not academic, and states are again considering the creation of quarantine facilities for tuberculosis patients (Maine Department of Health and Human Services, 2008, pp. 373-393). And as AIDS emerged, even some health care professionals thought that patients with AIDS should be quarantined (Barrick, 1988; Parmet, 1985), giving new resonance to the historical example of the banishment of lepers (Chejfec, 1995). Today, people who are HIV positive continue to be denied access to programs in some settings (ACLU 2007). In short, the use of coercion to gain access to care and/or to protect the public is not confined to people with mental illnesses but is a tool used in other public health contexts.

\section{Interventional law: Mental illnesses, other legally permitted forms of coercion, and legislative efforts to assure population health.}

While involuntary civil commitment statutes may be the paradigmatic example of infrastructural law as applied to people with mental illnesses, not all legally sanctioned strategies designed to achieve treatment adherence in community settings are necessarily coercive. Wertheimer, a political scientist, suggests that analysis of the coercive properties of a particular intervention depends on whether it would worsen or improve the person's baseline position (Wertheimer, 1990). Some commentators, extending Wertheimer's framework, have argued that it is counterproductive to debate the use of mandates in community care settings as a matter of

Mental Illness, Law, and a Public Health Law Research Agenda 
coercion versus civil liberties. Rather they argue that the language of contract law creates a more useful descriptive vocabulary for empirical research that can revitalize a discussion often stalemated by debates over rights (Bonnie \& Monahan, 2005). Whether efforts to induce treatment adherence are formally coercive may depend in part on the intervention in general, and how it is applied in particular circumstances. In community settings, there have been a variety of legally permitted strategies designed to achieve public health outcomes. These include outpatient civil commitment (discussed above), conditioning access to housing and money on adherence to treatment, and imposition of treatment conditions in the criminal justice system to avoid incarceration. In each case, the assumption is that gaining sustained access to care is both an independent value and essential in reducing public risk. Housing, money, and interventions staged by the criminal justice system are discussed briefly below.

Housing and money. While outpatient commitment has drawn the most attention in debates regarding coercion in community settings, various individuals, including treatment providers, housing officials, family members and criminal justice officials use coercion and other inducements to obtain treatment adherence, based on the (unproved) assumption that sustained tenure in treatment will reduce public safety risk.

In a study of 1,011 psychiatric outpatients in public mental health outpatient programs in five sites throughout the United States, Monahan and colleagues collected self reports of prior experiences in which certain goods (access to housing, access to money) had been conditioned on treatment adherence, or where the person had been subject to a civil or judicial order mandating treatment. Different legal principles govern these transactions. For example, substituted decision making over money can be accomplished through guardianship or the establishment of a representative payee. A representative payee may be appointed when an 
individual becomes incapable of managing Social Security or Supplemental Security Income (SSI) payments (for a description, see www.ssa.gov/payee) and in many circumstances, a family member or treatment provider assumes that role. Housing providers also have discretion to condition continued residence upon compliance with treatment and other behavioral conditions, discretion that is exercised particularly by providers of "supported housing" for people with mental illness. Conditioned access to the goods of housing and money is a frequent experience in the lives of people with mental illnesses: Monahan and associates found that between 23 and 40 percent of participants across the sites reported that access to housing had been made contingent on treatment compliance (Monahan et al., 2005). In addition, approximately 7 to 19 percent of respondents in the five-site study reported that they had an experience in which access to money was made contingent on treatment compliance. Whether conditioned access has an impact on the health of the person, or the safety and health of the broader community, are distinct questions with little empirical evidence to date.

Criminal justice. There have also been extensive efforts to divert people with mental illnesses from the criminal justice system into treatment, in response to a dramatic increase in the number of people with mental illnesses entering the criminal justice system. In a recent study of a sample of 822 inmates in two Maryland and three New York jails, use of the Structured Clinical Interview for DSM-IV (Diagnostic and Statistical Manual of Mental Disorders, Fourth Edition) (SCID) showed that 14.5 percent of male and 31 percent of female inmates had a current serious mental illness (Steadman et al., 2009). Assuming similar prevalence among all arrestees, Steadman and colleagues infer that more than two million people with serious mental illnesses are booked into US jails in a given year. Overall prevalence of mental illness and substance abuse disorders among people in correctional facilities approaches 80 percent and may

Mental Illness, Law, and a Public Health Law Research Agenda 
be even higher for juveniles (Teplin, Abram, McClellan et al., 2002). These are much higher prevalence rates for serious mental illnesses in the general population (Kessler, Chiu, Demler, Walters, 2006). In some cases, diversion occurs prior to arresting and booking the person for an offense. The goal of pre-booking diversion is to provide access to appropriate care without formal involvement of the criminal justice system (Hartford, Carey, \& Mendonca, 2006). Insofar as these strategies often depend on police officers identifying people who might be appropriate for diversion, changing police practice has been a particular focus. A notable example is Crisis Intervention Training (popularly known as CIT). Developed in Memphis, this training rests on a standardized 40-hour curriculum for police officers. The curriculum instructs officers about mental illness, local treatment resources, and techniques for identifying and apprehending people with mental illnesses in ways that minimize the prospect of violence and enhance opportunities to access the treatment system (National Alliance for the Mentally Ill, 2010).

Therapeutic courts, including mental health courts, have also emerged in the last decade Raines \& Laws, 2009). Mental health courts seek to divert individuals with mental illnesses into care post-booking. While participation in treatment courts is voluntary, courts retain the option to sanction a person for non-adherence to treatment and other conditions imposed by the court. In this respect, therapeutic courts represent another effort to blend respect for the person's autonomy (through voluntary agreement to enter the court) with the use of leverage (the court's use of jail and other sanctions) to achieve the twin goals of access to care and protection of public safety.

Finally, other people enter treatment after conviction for a crime, as a condition of sentencing. Today there are more than five million people in the US on probation or parole (Pew Center on the States, 2009), many with serious mental illnesses. Probation and parole officers 
may use correctional supervision as leverage to ensure treatment adherence on the part of probationers and parolees with mental illness. Just as the growing number of people with serious mental illnesses in the criminal justice system has caused changes in police and judicial behavior, a number of jurisdictions in the US have adopted specialty probation programs for probationers with mental illnesses. The touchstone of such programs is specialized training and a reduced caseload for the specialty probation officer, who then monitors compliance with both the ordinary conditions of probation and special conditions regarding mental health treatment.

It is worth noting that few of these strategies are applied exclusively to people with mental illnesses. There are approximately seven million people with representative payees (Committee on Social Security Representative Payees, 2007) and it is estimated that more than one million of those individuals have psychiatric disabilities (Elbogen, 2010). Therapeutic courts exist in many other contexts, such as drug courts and juvenile courts, and access to publicly funded housing is often made conditional on avoidance or adoption of certain behaviors beyond those associated with mental illness. And when applied to people with mental illnesses, the strategies tend to focus on the most ill and the most impoverished, given that these are the subgroups of people with mental illnesses most likely to come into contact with criminal justice and other public welfare and social control agencies.

\section{Legislative efforts to protect the public through excluding people with mental}

\section{illnesses: Access to guns.}

As discussed, the law permits access to goods such as housing and money to be conditioned on adherence to treatment, based on the assumption that treatment will have a positive effect on public health outcomes. However, in other circumstances, legislation assumes that public health

Mental Illness, Law, and a Public Health Law Research Agenda 
is best assured by simply denying access to a good to those with mental illnesses. An example is access to guns.

Gunshot injuries have created an enormously expensive public health issue, in personal and financial costs (Wintermute, 2008). Yet it has been difficult to address the root causes of the issue, because gun ownership is woven into the fabric of United States constitutional law. Exclusions from gun ownership are rare, but they do exist, for example, for citizens with mental illnesses.

It is not surprising that legislation still sometimes adopts deep-seated public assumptions about the dangerousness of people with mental illnesses, assumptions that may have become more entrenched over the years (Pescosolido, Monahan, Link, Stueve, \& Kikuzawa, 1999; Appelbaum \& Swanson, 2010). The federal Brady Handgun Violence Prevention Act (P.L. 103$159,1993)$ is an example of legislation based on those assumptions. The legislation prohibited certain individuals, including someone "adjudicated as a mental defective or committed to a mental institution," from possessing firearms and required background checks to assure potential purchasers did not fall into one of these groups. Many state legislatures have also imposed restrictions on gun purchases by some groups of people with mental illnesses (Norris, Price, Gutheil, \& Reid, 2006). After the Virginia Tech killings, Congress enacted legislation (H.R.2640, 200) authorizing more than one billion dollars in grants to states to improve the tracking and reporting of individuals who are legally barred from purchasing guns. Some advocates have argued that enhanced reporting requirements further stigmatize people with mental illnesses and might prevent some individuals from seeking treatment (Shern, 2007). However, those arguments have been unpersuasive. While the United States Supreme Court 
forcefully struck down legislation barring handguns in the District of Columbia, the Court also noted that nothing in its opinion "should be taken to cast doubt on longstanding prohibitions on the possession of firearms by felons and the mentally ill, or laws forbidding the carrying of firearms in sensitive places such as schools and government buildings, or laws imposing conditions and qualifications on the commercial sale of arms" (District of Columbia v. Heller, 554 U.S. _ 2008). The Court's recent decision in McDonald v. Chicago (561 U.S.__2010) essentially extended to the States the Heller court's opinion with respect to gun rights. The Court's decisions have reified without resolving the two conflicting impulses that inform gun control legislation, which are to deny access to a small class of the putatively dangerous while assuring easy access for everyone else (French, 1995). Regardless, it is difficult to see the Court's reasoning as anything other than acceptance of the general assumption that people with mental illnesses as a class are more dangerous than not, and as a class are more dangerous than other citizens.

\section{Psychiatric advance directives}

While coercion and other types of leverage can restrict individual autonomy, psychiatric advance directives (PADs) are an effort to expand patient autonomy and reduce the need for coercive action against a person with mental illness, particularly in a crisis. The introduction of PADs is regarded as one of the more significant developments in US mental health law and policy in recent years (Appelbaum, 1991; Appelbaum, 2004; Srebnik \& Lafond 1999). Thomas Szasz in 1982 proposed the "psychiatric will" as a way to legally protect patients against unwanted mental health intervention; the origin of PADs thus resonates with the civil rights focus of the constitutional era of mental health law. However, PADs also have origins in medical advance directives, powers of 
attorney for health care, and "living wills" for end-of-life care and accordingly fall within a public health law framework.

While most states prior to the 1990s had statutory provisions for medical advance directives, interest in and use of these instruments increased dramatically following the US Supreme Court's decision in Cruzan v. Director, Missouri Dept. of Health (1990), which ruled that it was permissible for states to require "clear and convincing evidence" of patients' wishes in order to withdraw lifesustaining treatment. Soon thereafter, Congress enacted the federal Patient Self-Determination Act (PSDA) (Omnibus Budget Reconciliation Act, 1990) to promote the use of written advance directives (ADs). The PSDA requires healthcare facilities receiving federal funds to ask patients upon admission whether they have executed an $\mathrm{AD}$ and to inform patients of their rights to prepare one (Greco, Schulman, Lavizzo-Mourey, Hansen-Flaschen, 1991).

In the wake of the PSDA, mental health consumer advocates urged the application of these instruments to the context of decisional incapacity associated with psychiatric crises. Persons with serious mental illnesses were seen to be particularly vulnerable to loss of autonomy and at risk of receiving unwanted interventions during times of mental health crisis and thus seemed to be a logical target population for this legal intervention (Kapp, 1994; Hoge, 1994; Backlar, 1997). However, while medical ADs applied mainly to end-of-life care, PADs were designed to promote recovery. In contrast to the singular event of death, the episodic nature of incapacity in severe mental illness may provide the affected person with valuable experience regarding what to expect and how best to manage future psychiatric crises (Backlar, 1997; Halpern \& Szmukler, 1997).

Twenty-six states have enacted specific PAD statutes at the time of writing. Clearly, expansion of PAD legislation and policy in the US was driven in part by mental health consumer advocacy organizations' resistance to legal coercion in mental health care (California Protection and 
Advocacy, Inc., 2001). Concern over the expansion of coercion or "leverage" in community-based care (Monahan et al., 2005) led to a broadened view of PADs' potential role as an antidote or remedy for coercion - an alternative vehicle for "self-directed care" (Srebnik \& La Fond, 1999; Srebnik, Russo, Sage, Peto, \& Zick, 2003). Specifically, advocates hoped that PADs would give persons with severe mental illness greater control over their own treatment, decreasing the need for involuntary interventions (Appelbaum, 1991; Appelbaum, 2004; Winick, 1996).

As this summary suggests, there are many situations in which interventional law attempts to mold the behavior of individuals with mental illnesses in an effort to achieve various public health outcomes, including improved functioning, reduction of public risk and increased autonomy in making health decisions. Whether these efforts are successful creates a rich set of research questions discussed further below.

\section{Incidental Law: Legal efforts to expand voluntary access to services and social}

\section{supports}

While the law's concern with coercion and with dangerousness has dominated much of "mental health law", there have also been statutory efforts to expand access to care and to provide individuals with more autonomy over health care decisions. One of these efforts (the Americans with Disabilities Act) has a much broader focus than people with mental illnesses, focusing on all people who have a disability as defined by law. While not directed specifically at mental illness, the ADA has become an important part of the lives of many people with mental illnesses.

\section{The Americans with Disabilities Act}

The Americans with Disabilities Act (ADA) is an important example of the use of law to pursue a broad social policy that may improve the lives of people with mental illness. The ADA was intended to eliminate disability as a basis of discrimination in many spheres, including

Mental Illness, Law, and a Public Health Law Research Agenda 
employment and public services and accommodations. It was designed to enrich the lives of people with disabilities in many ways, including the attainment of important public health outcomes (for an overview, see National Council on Disability, 2007). At the time of passage, Congress estimated that approximately 43 million Americans had a physical or mental disability covered by the ADA (Melton, Petrila, Poythress, \& Slobogin, 2007). Two applications of the ADA to people with mental illnesses in community settings are relevant here: The first is in the context of employment, and the second is in the pursuit of a legal remedy for attaining access to services. It is worth noting that in contrast to many other substantive areas discussed in this paper, the ADA does not concern itself primarily or exclusively with those with serious mental illnesses.

If a person has a mental disability, as defined by the ADA, and can perform the essential functions of the job, the ADA requires that the employer make reasonable accommodation as necessary to enable the person to overcome the effects of the disability in the workplace. Mental disability is one of the leading causes of complaints under the ADA, and given the stigma associated with mental illness, a reasonable empirical question (discussed below) is whether claims based on mental impairment are treated similarly to claims based on physical impairments.

The ADA has also been the basis of litigation designed to assure access to community services for people who are confined despite the judgment of their treatment providers that their condition warrants treatment in community settings. In Olmstead v. L.C. (1999), the US Supreme Court held that such confinement can constitute illegal segregation under the ADA. In its decision, the Court's majority was forthright in its description of the harm caused by inappropriate institutional confinement.

Mental Illness, Law, and a Public Health Law Research Agenda 
First, institutional placement of persons who can handle and benefit from community settings perpetuates unwarranted assumptions that persons so isolated are incapable or unworthy of participating in community life...Second, confinement in an institution severely diminishes the everyday life activities of individuals, including family relations, social contacts, work options, economic independence, educational advancement, and cultural enrichment... In order to receive needed medical services, persons with mental disabilities must, because of those disabilities, relinquish participation in community life they could enjoy given reasonable accommodations, while persons without mental disabilities can receive the medical services they need without similar sacrifice. ( $p$ 600.)

While the Court was unstinting in describing the impact of institutionalization on the individual (reminiscent of language used by courts in constitutional litigation challenging institutional conditions), it created defenses for States that to date have limited broad application of Olmstead. The lower federal courts have read Olmstead quite narrowly, holding, for example, that the ADA did not obligate a State to create new resources or, in the context of Medicaid, to offer services not already offered under the State's Medicaid plan (Smith \& Calandrillo, 2001). Courts have ordered community placement for individuals confined to nursing homes, facilities for people with mental retardation and developmental disabilities, and psychiatric facilities, but typically have ruled in favor of States that appeared to be making active efforts to effectuate change even when individuals spent years on waiting lists for services (Rosenbaum \& Teitelbaum, 2004).

A more recent case applies Olmstead much more expansively. If upheld on appeal (not a certainty), it will create for the first time a legal tool for changing mental health systems and not simply conditions for small groups of individuals. In Disability Advocates v. Paterson (2009), Judge Garaufis ruled that the State had discriminated against more than 4,300 individuals living in large, private group homes licensed by the State when it did not provide them with the opportunity to move into apartments and homes of their own, with appropriate social services and mental health treatment. The court described the adult homes as segregated institutions that 
removed residents from the community and impeded their interactions with people without disabilities. While the court acknowledged that the State would have to develop additional supported housing to place the 4,300 individuals living in the affected adult homes, the court also found that this would not require additional spending by the State. At the time of writing, the court has directed the State of New York to create several thousand community placements for the defendants, and the United States Department of Justice has joined the case on behalf of the plaintiffs.

\section{Part 2: State of the Research: What do we currently know?}

Public health law should have an impact on public health outcomes, and the overarching question of whether it does raises numerous public health law research issues. Burris and colleagues (2010) define public health law research as "the scientific study of the relation of law and legal practices to population health. This includes both direct relationships between law and health, and relationships mediated through impacts of law on health behaviors and other processes and structures that affect population health.” In the last 30 years, research of this nature has begun to shed light on the impact of law on people with mental illnesses, in each of the substantive legal areas discussed above. We organize this discussion by relying on the domains (infrastructural, interventional, incidental) that we relied on in discussing the application of law to that part of the population with mental illnesses. As noted ${ }^{2}$, there is no rigid rule regarding which domain a particular type of project must be placed.

Research to date has focused principally on these core questions:

\footnotetext{
${ }^{2}$ See footnote 1 .
} 
1. Does the empirical relationship between mental illness and violence warrant a strong emphasis on dangerousness and risk management in mental health policies and laws? That is, do people with mental illnesses represent the public risk that many assume they do?

2. What is the impact of infrastructural law, such as formal outpatient civil commitment legislation, on public health outcomes such as public safety and access to care for people with (otherwise untreated) serious mental illness?

3. What is the impact of interventional law and policy, such as the provision of subsidized housing and the use of representative payeeship to manage a person's money, on public health outcomes such as treatment adherence, access to care and public safety?

4. Is the impact of incidental law, such as the ADA as applied to people with mental illnesses, equitable by comparison to the impact on people with physical illnesses and does it have other, collateral effects on issues such as access to health care and (perhaps as a distal indirect outcome) criminal recidivism?

5. Are legal efforts to expand autonomy for people with mental illnesses, such as psychiatric advance directives, broadly adopted, and if so, do they result in access to care more closely aligned with the person's wishes?

The discussion begins with the overarching issue of the relationship between mental illness and violence, an issue that has always been at the heart of mental health law and policy.

\section{Mental illness and violence:}

Social scientists have held competing views regarding the relationship between mental illness and violence, competing views that each have shaped legal policy. On the one hand, the tradition of social-psychiatric epidemiology has addressed the problem within a public health 
framework, using survey research tools and clinical assessment to identify risk and protective factors for violence (e.g., Swanson et al., 1990; Steadman et al 1998; Monahan et al., 2005; Catalano \& McConnell, 1996). This line of scientific work has been driven largely by an applied policy-research agenda of protecting the public; the goal has been to understand the relationship, if any, between violence and mental illness for the purpose of improving risk assessment and risk management. On the other hand, the tradition of the sociology of deviance and social control has studied public perceptions of the link between mental illness and violence to understand how society labels, represents, and responds to deviance; the nature and function of social stigma; and how perceptions of dangerousness may produce social discrimination. (Goffman, 1961; Link \& Phelan, 2001; Corrigan et al., 2005; Pescosolido et al., 2007) For this tradition, the applied research agenda has been driven largely by a reform concern for the civil rights, autonomy, and well-being of individuals diagnosed with mental illness, rather than a focus on protecting the public from such persons. Each of these perspectives and the tension between them has shaped the development of legal principles applied to people with mental illnesses.

To address these issues, a robust body of research has emerged that relies on analysis of data drawn from national epidemiological studies (Swanson, 1994), interviews with psychiatric patients and collaterals such as family members (Swanson, Swartz, Van Dorn, Elbogen, et al, 2006), and comparisons of discharge psychiatric patient samples with matched community samples residing in the same neighborhoods (Steadman, Monahan, Mulvey, Robbins, et al. 1998). Studies have also assessed the role of psychopathology as a contributing factor in violence within a multivariable framework of clinical, demographic, and socio-environmental risk factors (Swanson et al., 2002; 2008). Three conclusions are worth noting. First, there is a modest, but significant relationship between mental illness and violence, a relationship greatly 
extended when a person has a co-occurring substance abuse diagnosis, and people with a major mental illness and a diagnosis of substance abuse are much more likely to engage in community violence than those with only a mental illness diagnosis. Second, the prevalence of violence among people discharged from a hospital with a mental illness but no substance abuse diagnosis is approximately the same as the community prevalence of violence in the same neighborhoods where the patients resided. Third, factors associated with violence go far beyond mental illness, to the sorts of factors that distinguish many people at risk for health problems. As Appelbaum (2006) has observed, variables identified as increasing violence risk include socioeconomic status and the characteristics of the neighborhood in which a person resides; he concludes by asserting that "given the relatively modest contribution to the overall risk of violence by persons with mental disorders, the likelihood and magnitude of adverse effects from any intervention must be carefully considered before it is embodied in law". In short, most factors associated with violence among people with mental illnesses are not uniquely associated with mental illness, but rather are those factors associated with violence among the population at large, including those factors linked to poor public health.

\section{Infrastructural law research.}

Outpatient civil commitment has drawn the most attention at a policy level, and it has attracted a comparatively large investment in implementation research. Single jurisdiction studies have examined the impact of outpatient civil commitment on rehospitalization, involvement with the criminal justice system, and other public health outcomes. In North Carolina, research found that extended involuntary outpatient commitment (six months or more) combined with intensive mental health services in the community reduced future hospitalizations (Swartz, Swanson, Wagner et al., 1999), violent behavior (Swanson, Swartz, Borum, et al., 2000), arrests (Swanson, 
Borum, Swartz, et al., 2001), and criminal victimization (Hiday, Swanson, Swartz, et al., 2002), while it improved treatment adherence (Swartz, Swanson, Wagner, et al., 2001), and the subjective quality of life for people with serious mental disorders (Swanson, Swartz, Elbogen, et al., 2003).

The most important finding was that neither treatment nor a court order alone had these effects, but that both treatment and judicial involvement were essential. A more recent evaluation of Kendra's Law (New York's assisted outpatient treatment law) utilized mixed methods, including quantitative analysis of Medicaid claims, arrest records and other archival data, and resulted in similar findings regarding reduced hospitalization and re-arrest rates associated with assisted outpatient treatment. The study also found that people assigned to assisted outpatient treatment had increased levels of service utilization such as assertive community treatment and intensive case management and appropriate medication (Swartz, Swanson, Steadman, et al 2009).

Another study used suicide statistics as an independent variable to determine whether introduction of the dangerousness criteria in each state increased the incidence of suicide. The authors examined suicide rates in all states 15 years prior to and after the state incorporated dangerousness into its civil commitment law. While the authors could not demonstrate a clear link between the changed statutory criteria and suicide rates, the study is interesting because it took an indicator of public health (suicide statistics) to determine whether statutory reform designed to protect individual civil rights had an unanticipated negative effect on public health (Large, Nielssen, Lackersteen, 2009). 
Finally, a recent mapping study compared mental health legislation across 32 Commonwealth nations with two models (the World Health Organization Mental Health Policy and Service Guidance Package-Mental Health Legislation \& Human Rights, and the Council of Europe's Recommendation concerning the protection of human rights and dignity of persons with mental disorder). The purpose was to determine whether common ethical and legal principles were the foundation for mental health legislation in the disparate Commonwealth countries (Fistein, Holland, Clare, \& Gunn, 2009) and how national legislation compared with the consensus statements developed by WHO and the Council of Europe. The authors developed a multi-axial framework from the statements by WHO and the Council. The axes included diagnosis, exclusion criteria, therapeutic aim, risk, capacity, and review processes that were available to someone subject to involuntary treatment. The authors concluded that legislation in Commonwealth nations varied, both across countries and when compared to the consensus recommendations and they also found among other things, a trend toward the adoption of statutory criteria that combined a low risk threshold and a low incapacity threshold for the use of coercion, effectively expanding the state's authority to impose mandatory treatment.

\section{Interventional law research.}

Intervention studies can examine the effect of a legal intervention on health outcomes or mediating factors influencing health outcomes. While outpatient commitment has dominated policy debates and legal commentary, there have also been a handful of studies of other strategies designed to induce treatment adherence, access to health services, and reduce public risk. A self-report study of the use of leverage and coercion among a large sample of community outpatients found that the use of leverage was more likely to occur in "special" housing, 
available only to people with mental illnesses and designed explicitly to provide treatment with housing (Robbins, Petrila, LeMelle, \& Monahan, 2006). However, residents in special housing and in housing-first programs (that is, housing for people with mental illnesses where treatment participation is not mandatory) reported no significant differences in overall satisfaction with their residence (Robbins, Callahan, \& Monahan, 2009).

In handling money for individuals with mental illnesses, family members and clinicians often become representative payees. In a study of 50 dyads of consumers with psychiatric disabilities and family members acting as representative payees, Elbogen and colleagues (2007) found that the majority of consumers and family members believed that the arrangement led to enhanced living stability. However, 36 percent of consumers and 50 percent of payees reported conflicts over money, and many payees lacked basic money management knowledge and skills. Another study of 205 adult patients in a large urban community mental health center found that 53 percent of patients had a money manager or payee, and 79 percent of this group had a clinician as payee. A large percentage (40 percent) of those with a clinician payee reported that they believed that the payee had conditioned access to and use of money on treatment adherence; the authors concluded that when a clinician acted as payee, it appeared to increase the risk of conflict in the therapeutic relationship because of the clinician's use of money as a source of leverage (Angell, Martinez, Mahoney, \& Corrigan, 2007).

There have also been intervention studies of strategies used by criminal justice authorities to divert people into treatment and reduce public risk. Single site studies using arrest and service use data, along with self reports by individuals in both court enrolled groups and comparison groups suggest that mental health courts may increase access to a range of services while reducing time to arrest and time spent in jail (Cosden, Schnell, Yasmeen, \& Wolfe, 2003; 
Poythress, Petrila, McGaha, \& Boothroyd, 2002; Redlich, 2005; Ridgely, Engberg,Greenberg et al, 2007; McNeil \& Binder, 2007). In addition, evidence suggests that individuals appearing before these courts experience low levels of perceived coercion and believe they are given voice, something that theoretically might enhance their receptivity to treatment and to rule-abiding behavior (Tornblom \& Vermunt, 2007; Tyler, 2005). More recently, a four-site, four-court study has been completed by the MacArthur Research Network on Mandated Community Treatment. This is the first multiple court study of mental health courts, and findings from the study should be released shortly.

Skeem and colleagues have conducted mixed method (focus groups with probationers and probation officers, analysis of service use and arrest data) studies comparing special probation for people with mental illnesses and traditional probation. According to Skeem and colleagues $(2007 ; 2008 ; 2009)$, there are significant differences between regular and specialty mental health probation in the manner in which violations are handled (traditional probation officers are more likely to report violations than specialty officers), as well as the characteristics of the relationship between the officer and probationer. Specifically, the investigators found evidence that the quality of the relationship between specialty officers and probationers was the key mechanism that resulted in improved compliance with the conditions of probation as well as the reduction in violations for those on specialty probation. As with outpatient commitment and therapeutic courts, specialty probation officers with specialized mental health caseloads appear to be effective in facilitating access to care and adherence to prescribed treatment, which may result in better mental health and criminal justice outcomes for probationers.

There have also been a number of mixed method studies done on the impact of psychiatric advance directives, a legislative effort to expand autonomy for people with mental 
illnesses. A study funded by the MacArthur Network on Mandated Community Treatment in five US cities (combined $\mathrm{N}=1,011$ ) found a large latent demand for these legal instruments (Swanson, Swartz, Ferron et al., 2006). The study reported that PADs were completed by only 4 to 13 percent of mental health consumers sampled from public-sector outpatient treatment, yet large majorities 66 to 77 percent - indicated that they would want to complete PADs if given the opportunity and necessary assistance.

Despite this apparent interest on the part of consumers, the expected widespread use of PADs has yet to materialize, due to skepticism and lack of familiarity with PADs by clinicians, slow progress in implementing and integrating them into routine care, and lack of resources to assist consumers in preparing PADs (Van Dorn et al., 2006). These barriers are not insurmountable: A large, longitudinal implementation trial in North Carolina found that a formal, structured intervention to facilitate PADs can help consumers with serious mental illness understand and complete legal PADs, and completed facilitated PADs tend to contain treatment instructions that comport with clinical standards of care as well as consumers' personal goals for treatment (Swanson, Swartz, Elbogen et al., 2006; Elbogen et al., 2007).

Evidence to date suggests that PADs, if widely implemented, could improve the health of the population with mental illness (Swanson et al., 2008.) However, far more needs to be learned about how best to facilitate PAD completion, especially within fiscally-constrained mental health care systems. Information is lacking in how to overcome barriers to PADs at the clinician level as well as the consumer level. Research is needed to better identify the populations that could most benefit from PADs and under what conditions. Also needed is research regarding the mechanisms the pathways of effect - by which PADs may benefit consumers and whether subgroups of interest, such as those under mandated community treatment, may benefit differentially. 


\section{Incidental Law Research}

The Americans with Disabilities Act was enacted to create better opportunities for all people with disabilities. It did not focus specifically on mental illness, but treated physical and mental disabilities equally. This provided the opportunity to determine whether people with mental disabilities fared as well in pursuing claims under the ADA as people with physical disabilities, a fair question given the stigma that has been associated with mental illnesses and assumptions about the relationship between mental illnesses and violence.

A study by Swanson, Burris, Moss, Ullman, and Ranney (2007) addressed this latter question by comparing characteristics, perceptions, legal processes, and outcomes in litigation for persons with psychiatric and non-psychiatric disabilities who filed employment discrimination lawsuits under Title I of the ADA from 1993 to 2001. The study found that people with psychiatric disability fared significantly worse in employment discrimination lawsuits than their counterparts with non-psychiatric disabilities, controlling for other significant predictors of litigation outcome. Plaintiffs with mental impairments were also significantly less satisfied with the overall process of filing a discrimination claim and filing a lawsuit under the ADA. Earlier studies concluded that for ADA charges filed with the Equal Employment Opportunity Commission from January 1, 1999 through June 30, 2000, individuals with psychiatric disabilities were slightly but significantly less likely to have the EEOC refer their case for mediation, and employers were significantly less willing to mediate with clients with psychiatric disabilities compared to those with non-psychiatric disabilities (Moss, Swanson, Ullman, \& Burris, 2002). These studies did not show why these differences exist, but the findings are important in the context of larger public attitudes about mental illnesses and their potential 
impact on administration of laws that have as one of their goals enhancement of public health outcomes.

\section{Summary}

How might we characterize the current state of our knowledge on five of the most researched questions about the application of law to people with mental illnesses?

\section{What is the relationship between mental illness and violence and do people with mental illnesses represent the public risk that many assume they do?}

Psychiatric patients who are discharged following acute hospitalization arguably comprise the most relevant population for public health law research on the question of violence risk, because the question of dangerousness is encoded in the legal criteria for involuntary hospitalization and also is brought to bear on discharge decisions. In that context, the "gold standard" for research on patient violence is still the risk study conducted by the MacArthur Research Network on Mental Health Law. The study was well designed and implemented, and while a single study always would benefit from replication, it is fair to say that the relationship between mental illnesses and the risk of violence is far less than that imagined by the public and many policymakers. It also seems clear that the major exacerbating factor for people with and without mental illnesses is substance abuse, a finding that may call into question that continuing emphasis of inpatient and outpatient civil commitment on mental illness.

2. What is the impact of infrastructural law, such as outpatient civil commitment legislation, on public health outcomes such as access to care and public safety? 
The evidence gathered to date, in mixed method studies in North Carolina and New York, suggests that outpatient commitment orders, combined with a fairly lengthy treatment dose, can result in good public health outcomes for committed individuals without increasing the risk to public safety. However, outpatient commitment is affected strongly by jurisdictional characteristics ranging from the attitude of law enforcement and treatment providers to the service capacity available to provide treatment (Ridgely, Borum, \& Petrila, 2001). Therefore, we cannot yet say conclusively that outpatient treatment "works", only that the available evidence suggests that it can be associated with improved public health outcomes.

\section{What is the impact of interventional law, such as the use of legally sanctioned mandates exercised by legal officials and others on access to care and public safety?}

This is an increasingly researched area. One interesting finding from the study of housing referenced above was that individuals who reported experiencing higher perceived coercion did not report more dissatisfaction with their housing. This and studies of perceived coercion in the context of voluntary versus involuntary hospital admissions (Hoge, et al, 1997) suggest that coercion, at least as perceived by the recipient, does not have a single, predictable affect on satisfaction with services.

Findings from studies of interventions mounted from the criminal justice system also lean in the direction of showing good public health outcomes and reduced criminal justice involvement. Skeem and colleagues' work on probation in particular creates a hypothesis that the quality of the relationship between the legal official (in this case the probation officer) and the individual may be the significant point of leverage through which these outcomes occur. This is discussed in more detail in Part 3 of the paper.

Mental Illness, Law, and a Public Health Law Research Agenda 
4. Is the impact of incidental law, such as the ADA as applied to people with mental illnesses, equitable with the impact on people with physical illnesses and does it have other, collateral effects on outcomes such as access to health care and criminal recidivism?

Studies of the ADA suggest that the ADA is applied differentially in the treatment of employment claims, with claims based on mental disabilities disadvantaged. While employees with mental disabilities appear to fare less well than those with physical disabilities in pursuing ADA claims, all employees were affected by a series of decisions by the US Supreme Court that narrowed the application of the ADA and made it increasingly difficult for employees to prevail. Those decisions interpreted the ADA in a way that constricted the group of people who might be found to have a disability and thereby receive the protection of the Act. In response, Congress in 2008 enacted legislation designed to restore the ADA to its original intent (Petrila, 2009). These amendments may stimulate an increase in ADA claims for both physical and mental disabilities. Whether the seeming disparities in outcomes between the two types of claims persist is a subject for further research.

\section{Are legal efforts to expand autonomy for people with mental illnesses, such as} psychiatric advance directives, adopted, and if so, do they result in access to care more closely aligned with the person's wishes?

Available evidence indicates that there are significant problems in gaining broad adoption of PADs. There is some evidence that a structured intervention designed to increase adoption can work, but it is not clear whether that intervention can be more broadly applied beyond the 
jurisdiction in which it occurred. There is also modest evidence that psychiatric advance directives can improve health outcomes, but beyond that, the knowledge base is quite sparse.

In short, we know far more than we did even a decade ago about the impact of the law on public health outcomes for people with mental illnesses. However, our knowledge base on most important questions is more suggestive than conclusive about inferences that can be drawn with good confidence. As the concluding part of this paper will illustrate, there is a need for additional research into some of the questions discussed above, as well as the possibility of opening interesting new areas of inquiry.

\section{Part 3: A framework for researching the impact of law on public health and related outcomes for people with mental illnesses}

There is a rich landscape for future public health law research focused on mental illnesses, in part because the assessment, treatment and management of mental illnesses now occurs in many different justice, health, social welfare, and educational settings where law or legal actors play significant roles. We are also in an era marked by sometimes obvious and sometimes subtle retreats from viewing interventions with people with mental illnesses primarily through the lens of civil rights. Rather, the policy focus today is on gaining access to health care for people with mental illnesses (as it is for many people with health issues generally). Questions of access are important to many people with mental illnesses who will never experience any coercion or other form of mandate, and who will never be considered a risk to self or others. In this context, achieving public health outcomes may depend more on reforming and legally reframing the

Mental Illness, Law, and a Public Health Law Research Agenda 
organization and financing of mental health services to improve access, eliminate disparities, increase fairness and dilute the need for coercion through better treatment engagement. Finally, there are basic questions that we are only beginning to explore. We have evidence suggesting that some of the law's efforts to improve public health outcomes and protect the public have borne fruit. However, we know virtually nothing about how or why that occurs, and for which specific target groups and subpopulations legal interventions have been most effective.

\section{Infrastructural studies}

All states have distinct statutory and regulatory provisions designed to improve access to care, create legal parameters for the exercise of coercion, set standards for licensed programs, address financial issues, and articulate the rights of people with mental illnesses. There are a number of studies that could explore the characteristics and implementation of these provisions, using a variety of methods.

\section{Mapping studies}

Most state mental health statutes were written in an era when the state mental health agency was the primary provider of services, through its operation of state psychiatric institutions. Few states have comprehensively revised their statutes since then, choosing instead to adopt amendments to address specific initiatives such as codification of a patient bill of rights, to incorporate outpatient commitment into the involuntary commitment law, or to change financing of the system. As noted earlier, Fistein and colleagues (2009) recently published results of a comparative mapping study of 32 Commonwealth nations' statutory schemes for involuntary treatment. A mapping study of state mental health statutes could reveal the current state of 
statutory mental health law in important domains across jurisdictions. Such a study could include surveys of stakeholders to identify areas where "the law" is perceived as a barrier or help in achieving public health goals such as improved access to care.

\section{Implementation studies}

There are several areas where an infrastructural implementation study could occur. For example, most states have a version of outpatient commitment, and well designed research has examined the implementation of those statutes in at least two jurisdictions (North Carolina and New York, discussed above). However, it also appears that outpatient commitment laws are used sparingly if at all in some jurisdictions that have adopted them, including Florida and California, two of the most populated states in the US (Petrila \& Christy, 2008). More systemic study of how often and under what conditions such laws are used in other jurisdictions, and the reasons why, would significantly improve our understanding of one of the most controversial issues in public mental health.

Many states have also adopted legislation to establish parity between insurance coverage for physical and mental illnesses (though how parity is defined varies among the states, National Conference of State Legislatures, 2009). The purpose of this legislation is to increase access to care for people with mental illnesses and to eliminate inequalities in the treatment of mental and physical illnesses. A multimodal, interview based study of California's parity law, in effect since 2000, revealed that many people potentially affected by the law did not know about it and that the law had unintended consequences, including patients receiving more severe diagnoses than warranted in part because only certain diagnoses were covered by the legislation (Rosenbach, Lake, Williams, and Buck, 2009). Facets of this study could be replicated, including interviews 
with representative individuals potentially affected by parity legislation regarding their knowledge and understanding of the law. If legislation designed to increase access to services is unknown to the population in question, it certainly creates barriers to implementation.

Finally, states occasionally adopt sweeping statutory reform. Virginia presents a recent example, in the aftermath of the Virginia Tech killings. The statutory changes are designed to improve patient choice while increasing access to care, and not simply extend the reach of coercion, the more traditional response to well known acts of violence (Bonnie, Reinhard, Hamilton, \& McGarvey, 2009). This type of legislation provides an important opportunity to conduct an implementation study to assess whether and how the legislation is implemented and its effects on public health outcomes.

\section{Interventional Law Research}

While the number of well designed interventional law studies has grown, the field is hardly exhausted.

\section{Mechanism studies}

The underlying hypothesis of legal interventions for persons with mental illness involved in the justice system is that the intervention will provide a gateway to treatment, and that sustained treatment will lead to improved public health and criminal justice outcomes.

An overarching issue is whether the most frequently used interventions (therapeutic courts, special probation) work, for whom, and why. The studies done to date, though warranting replication, have begun to reveal tentative answers to the first two questions. However, there is virtually no empirical information available on the last question, which is the most important 
question. And a recent study suggests that the core assumptions underlying these interventions may lack empirical validity.

In a very important paper, Skeem, Manchak, and Peterson (2010) review all available studies of four types of diversion programs for people with mental illnesses (jail diversion, problem solving courts, specialty probation or parole, and jail transition/prison reentry programs). They conclude that "even evidence-based mental health services (i.e., those that reliably affect clinical outcomes) have not affected criminal justice outcomes". While they acknowledge that for at least a small subgroup of offenders mental illness may be causally related to criminal behaviors, they suggest that two alternative models provide a better theoretical framework for considering criminal offending by people with mental illnesses. One model, a criminological model, proposes that people with mental illnesses offend, not because they have a mental illness, but because they are poor and live in conditions that include unemployment, victimization, health problems and a generally marginalized population (Fisher \& Drake, 2007). The other model focuses on "individual and proximate risk factors for offending like antisocial cognition and criminal associates"; in both models people with mental illness usually end up engaging in criminal behavior for the same reasons that people without mental illnesses offend.

Skeem and her colleagues provide evidence that one of the primary mechanisms sought through the use of coercion and leverage (treatment) does not mediate the outcome (reductions in recidivism) sought by legal officials, even when a public health outcome (improvement in symptoms) is attained. They also suggest that the supervisory quality of some relationships (judge and defendant; probation officer and probationer) may mediate favorable outcomes. This 
suggests that mechanism studies examining in more detail how judges and probation officers (as examples) play their quasi-therapeutic, supervisory roles may yield more information about how better outcomes might be mediated.

\section{Incidental Law Research}

As noted in Part 2, studies suggest that mental disability claims under the ADA fare less well than physical disability claims. While the ADA is important it is not the only area where there may be differential treatment of mental and physical illnesses. For example, social security disability and Medicaid are essential tools in enabling people with mental illnesses to remain in community care. People with mental illnesses comprised approximately $35 \%$ of those receiving disability benefits in 2000. An implementation study could examine whether there is equitable treatment of mental and physical disabilities in making disability determinations and if not, the nature and impact of any inequities.

\section{A note on methods}

Burris and colleagues provide a rich menu of different methods that can be employed alone or in combination in public health law research (Burris, et al, Table 1). Public health law research on mental health has used various methods, and has a long tradition of interdisciplinary collaboration. Randomized clinical trials are relatively rare, for a number of reasons including reluctance on the part of criminal justice officials to permit random assignment (McGaha, Boothroyd, Poythress, Petrila, \& Ort, 2002). Quasi-experimental designs are more common (Skeem, Manchak, \& Peterson, 2010), though critiques suggesting that design problems make it 
difficult to draw good inferences about outcomes are increasingly common (Slinger \& Roesch, 2010).

While methodological rigor is always a concern in drawing causal inferences, the relative degree of rigor can be thoroughly explained and inferences appropriately qualified. The larger point is that there are extensive tools available to cross-disciplinary teams to conduct good public health law research in the context of mental health. In addition, there are approaches that can be taken that are gaining a foothold in public health research. As an example, researchers can now link social science data, such as results of interviews on health status, with geographic information science, which can place the data in the context of the spatial organization of the population in question; this method has been used to explore patterns of injury (Shuurman, Hamee, Fiedler, Bell, \& Simons, 2008) and racial and spatial relations as health determinants in an urban setting (Schulz, Williams, Israel, \& Lempert (2002). One can imagine the application of this method to topics such as civil commitment, in an effort to uncover the potential impact of living location on rates of commitment.

\section{Summary}

Mental health is an integral part of public health, and law applied to the population with mental illnesses is largely comprised of the same legal principles, put to the same ends, as public health law. This means that a public health law research agenda can include questions arising from legal efforts to shape and mediate public health outcomes for people with mental illnesses. Prior research has begun to fill important gaps in our knowledge about the relationship between law and mental illnesses, but there are significant opportunities to continue to refine this existing knowledge while doing innovative research on newly emerging questions. 


\section{References}

American Civil Liberties Union (ACLU) (2007). Alabama department of corrections continues to deny programs to HIV-positive prisoners. http://www.aclu.org/prisonersrights/alabama-department-corrections-continues-deny-programs-hiv-positive-prisoners. December 11, 2007.

Angell, B., Martinez, N. I., Mahoney, C. A., \& Corrigan, P. W. (2007). Payeeship, financial leverage, and the client-provider relationship. Psychiatric Services, 58, 365-372.

Arnold v. Arizona Department of Health and Human Services, 775 P. $2 d 521$ (Az. 1989). Appelbaum, P.S. (1991). Advance directives for mental health treatment. Hospital and Community Psychiatry, 42, 983-984.

Appelbaum, P.S. (2006). Violence and mental disorders: Data and public policy. American Journal of Psychiatry, 163, 1319-1321.

Appelbaum, P.S. (1994). Almost a Revolution: Mental Health Law and the Limits of Change. London: Oxford.

Appelbaum, P.S. (1991). Advance directives for mental health treatment. Hospital and Community Psychiatry, 42, 983-984.

Appelbaum, P.S. (2004). Psychiatric advance directives and the treatment of committed patients. Psychiatric Services, 55, 751-752,763.

Appelbaum P.S., Swanson J.W. (2010). Law \& psychiatry: Gun laws and mental illness: how sensible are the current restrictions? Psychiatric Services, 61(7):652-4.

Backlar, P. (1997). Anticipatory planning for psychiatric treatment is not quite the same as planning for end-of-life care. Community Mental Health Journal, 33 (4), 261-268.

Barrick, B. (1988). The willingness of nursing personnel to care for patients with acquired immune deficiency syndrome: A survey study and recommendations. Journal of Professional Nursing, 4, 366-372.

Bonnie, R. J. \& Monahan, J. (2005). From coercion to contract: Reframing the debate on mandated community treatment for people with mental disorders. Law and Human Behavior, 29, 485-503.

Bonnie, R. J., Reinhard, J.S., Hamilton, P., \& McGarvey, E.L. (2009). Mental health system transformation after the Virgnia Tech tragedy. Health Affairs, 28, 793-804.

Mental Illness, Law, and a Public Health Law Research Agenda 
Burris, S., Wagenaar, A., Swanson, J., Ibrahim, J.K.,Wood, J., \& Mello, M. (2010). Making the case for laws that improve health: A framework for public health law research. Milbank Quarterly, 88, 169-210.

California Protection and Advocacy, Inc. (2001) Advance Health Care Directives: Sacramento: California Protection and Advocacy, Inc.

Catalano, R.A. and McConnell. W. (1996). A time-series test of the quarantine theory of involuntary commitment. Journal of Health and Social Behavior 37, 381-387.

Chejfec, C. (1995). Comment: Disclosure of an adoptee's HIV status: A return to orphanages and leper colonies. John Marshall Journal of Computer \& Information Law, 13, 343-369.

City of Newark v. J.S. 279 N.J.Super. 178, 652 A.2d 265, 3 A.D. Cases 1834 (N.J.Super.Law Div. 1993).

Cole, D. (2009). Out of the shadows: Preventive detention, suspected terrorists, and war. California Law Review, 97, 693-750.

Committee on Social Security Representative Payees. Improving the Social Security Representative Payee Program: Serving Beneficiaries and Minimizing Misuse (2007). National Research Council of the National Academies. Washington DC: The National Academies Press.

Corrigan, P.W, Watson, A., Heyman, M.L., Warpinski, A., Garcia, G., Slopen, N., \& Hall, L.L. (2005). Structural stigma in state legislation. Psychiatric Services, 56, 557-563.

Cosden, M., Ellens, J., Schnell, J., Yasmeen, Y., \& Wolfe, M. (2003). Evaluation of a mental health treatment court with assertive community treatment. Behavioral Sciences \& the Law, 21, 415-427.

Cruzan v. Missouri Department of Health, 497 U.S. 261 (1990).

DHHS (1999). Mental Health: A Report of the Surgeon General. Rockville, MD: U.S. Department of Health and Human Services, Substance Abuse and Mental health Services Administration, Center for Mental Health Services, National Institutes of Health, National Institute of Mental Health.

Deutsch, A. (1949). The mentally ill in America: A history of their care and treatment from colonial times ( $2 \mathrm{~d}$ ed.). New York: Columbia University Press.

Disability Advocates v. Patterson, 598 F. Supp. 2d 289 (E.D.N.Y. 2009).

District of Columbia v. Heller, 554 U.S. _ (2008).

Eaton, W.W., Martins, S.S., Nestadt, G., Bienvenu, O.J., Clarke, D., \& Alexandre, P. (2008). The burden of mental disorders. Epidemiologic Reviews, 30, 1-14.

Mental Illness, Law, and a Public Health Law Research Agenda 
Elbogen, E. (2010). Improving representative payeeship for people with psychiatric disabilities and their families. ClinicalTrialsFeeds.org, at http://clinicaltrialsfeeds.org/clinicaltrials/show/NCT00924976.

Elbogen, R. B., Ferron, J. C., Swartz, M. S., Wilder, C. M., Swanson, J. W., \& Wagner, H. R. (2007). Characteristics of representative payeeship involving families of beneficiaries with psychiatric disabilities. Psychiatric Services, 58, 1433-1440.

Fisher, W., \& Drake, R. (2007). Forensic mental illness and other policy misadventures: Commentary on "extending assertive community treatment to criminal justice settings: Origins, current evidence, and future decisions". Community Mental Health Journal, 43, 545-548.

Fistein, E.C, Holland, A.J., Clare, I.C.H., \& Gunn, M.J.(2009). A comparison of mental health legislation from diverse Commonwealth jurisdictions. International Journal of Law and Psychiatry, 32, 147-155.

French, D.J. (1995). Biting the bullet: Shifting the paradigm from law enforcement to epidemiology; a public health approach to firearm violence in America. Syracuse Law Review, 45, 1073-1101.

Gelman, S. (1997). The law and psychiatry wars: 1960-1980. California Western Law Review, $34,153-175$.

General Accounting Office. (1977). Returning the mentally disabled to the community: Government needs to do more. Washington DC: United States Government Printing Office.

Goffman, E. (1961). Asylums: Essays on the condition of the social situations of mental patients and other inmates. Harpswell, Maine: Anchor Publishing.

Gostin, L. (1995). The resurgent tuberculosis epidemic in the era of AIDS: Reflections on public health, law, and society. Maryland Law Review, 54, 1-131.

Gostin, L. (2000). Public health law in a new century. Part 1: Law as a tool to advance the community's health. JAMA, 283, 2837-2841.

Gostin, L. (2008). A Theory and Definition of Public Health Law. Georgetown University: O’Neill Institute for National and Global Health Law Scholarship. Paper 8. At http://scholarship.law.georgetown.edu/ois_papers/8/

Greco, P.J., Schulman, K.A., Lavizzo-Mourey, R., \& Hansen-Flaschen, J. (1991). The Patient Selfdetermination Act and the future of advance directives. Annals of Internal Medicine, 115, 639-643.

Mental Illness, Law, and a Public Health Law Research Agenda 
Halpern, A. \& Szmukler, G. (1997). Psychiatric advance directives: Reconciling autonomy and nonconsensual treatment. Psychiatric Bulletin, 21, 323-327.

Hartford, K., Carey, R., \& Mendonca, J. (2006). Pre-arrest diversion of people with mental illness: Literature review and international survey. Behavioral Sciences \& the Law, 24, 845-856.

Hiday V. A., Swanson J. W., Swartz M. S., Wagner H. R., \& Borum W.R. (2002). The impact of outpatient commitment on victimization of persons with severe mental illness. American Journal of Psychiatry, 159(8), 1403-1411.

Hoge, S. (1994). The Patient Self-Determination Act and psychiatric care. Bulletin of the American Academy of Psychiatry \& the Law, 22, 577-586.

Hoge, S.K., Lidz, C.W., Eisenberg, M., Gardner, W., Monahan, J., Mulvey, E., Roth L., Bennett, N. (1997). Perceptions of coercion in the admission of voluntary and involuntary psychiatric patients. International Journal of Law and Psychiatry. 20(2), 67-81.

Institute of Medicine (2006). Improving the Quality of Health Care for Mental and SubstanceUse Conditions. Washington, DC: Institute of Medicine.

Kansas v. Hendricks, 521 U.S. 346 (1997).

Kapp, M. (1994). Implications of the Patient Self-Determination Act for psychiatric practice. Hospital and Community Psychiatry. 45:355-358.

Kessler, R.C., Chiu, W.T., Demler, O., Walters, E.E. (2006). Prevalence, severity, and comorbidity of twelve-month DSM-IV disorders in the National Comorbidity Survey Replication (NSCR). Archives of General Psychiatry, 62, 617-627.

Klapper, A.B. (1993). Finding a right in state constitutions for community treatment of the mentally ill. University of Pennsylvania Law Review, 142, 739-835.

Large, M.M., Nielssen, O.B., Lackersteen, S.M. (2009). Did the introduction of "dangerousness" and "risk of harm" criteria in mental health laws increase the incidence of suicide in the United States of America? Social Psychiatry \& Psychiatric Epidemiology, 44, 614-621.

Lessard v. Schmidt, 349 F. Supp. 1078 (1972).

Link, B., \& Phelan, J. (2001). Conceptualizing stigma. Annual Review of Sociology, 27, 363-385.

Lyon, E., \& Farmer, P. (2005). Anniversary essays responses: Inequality, infections and community based health care. Yale Journal of Health Policy, Law \& Ethics, 5, 465-473.

Mental Illness, Law, and a Public Health Law Research Agenda 
Maine Department of Health and Human Services (2008). Need for a State Based Quarantine Facility: Report to the Joint Standing Committee on Criminal Justice and Public Safety in response to P.L. 2007 C. 359 (LD 1290, March, 2008. At http://www.maine.gov/dhhs/reports/quarantine_facility.pdf.

Manderscheid, R.W., Atay, J.E., \& Crider, R.A. (2009). Changing trends in state psychiatric hospital use from 2002 to 2005. Psychiatric Services, 60, 29-34.

McGaha, A., Boothroyd, R.A., Poythress, N.G., Petrila, J., and Ort, R.G (2002). Lessons from the Broward County mental health court evaluation, Evaluation and Programming, 25, 125-135.

McDonald v. Chicago, 561 U.S. _ (2010).

McNeil, D., \& Binder, R. (2007). Effectiveness of mental health courts in reducing criminal recidivdism and violence. American Journal of Psychiatry, 164, 1395-1403.

Mechanic, D., \& Rochefort, D. A. (1990). Deinstitutionalization: An appraisal of reform. Annual Review of Sociology, 16, 301-327.

Melton, G.B., Petrila, J., Poythress, N.G., \& Slobogin, C. (2007). Psychological evaluations for the courts: A handbook for mental health professionals and lawyers ( $3^{\text {rd }} \mathrm{ed}$.). New York, NY: GuilfordReview of Sociology, 16, 301-327.

Millon, T. (2004). Masters of the Mind: Exploring the Story of Mental Illness from Ancient Times to the New Millenium. Hoboken, New Jersey: Wiley.

Monhan, J. (1992). Mental disorder and violent behavior: Perceptions and evidence. American Psychologist,47, 511-521.

Monahan, J., Redlich, A., Swanson, J., Robbins, P., Appelbaum, P., Petrila, J.,Steadman, J., Swartz, M. Angell, B. \& McNiel, D. (2005). Use of leverage to improve adherence to psychiatric treatment in the community. Psychiatric Services, 56, 37-44.

Moore v. Draper, 57 So. 2d 648, 1952.

Moss K., Swanson J., Ullman M., Burris S. (2002). Mediation of employment discrimination disputes involving persons with psychiatric disabilities. Psychiatric Services, 53(8): 988995.

National Alliance for the Mentally Ill. (2010). Crisis Intervention Team Resource Center. Retrieved from http://www.nami.org/template.cfm?section=CIT2

National Council on Disability (2007). The Impact of the Americans with Disabilities Act: Assessing the Progress Toward Achieving the Goals of the ADA. Washington DC: National Council on Disability.

Mental Illness, Law, and a Public Health Law Research Agenda 
Norris, D.M., Price, M., Gutheil, T., \& Reid, W.H. (2006). Firearm laws, patients, and the roles of psychiatrists. American Journal of Psychiatry, 163, 1392-1396.

Olmstead v. L.C. 527 U.S. 581 (1999).

Omnibus Budget Reconciliation Act (OBRA) of 1990; formerly this Act was called the "Patient Self Determination Act of 1990.” Sec. 4206: Medicare Provider Agreements Assuring The Implementation of A Patient's Right to Participate in and Direct Health Care Decisions Affecting the Patient. Public Law no. 101-508.

Parmet, W.E. (1985). AIDS and quarantine: The revival of an archaic doctrine. Hofstra Law Review, 14, 53-90.

B.A. Pescosolido, B.L. Perry, J.K. Martin, J.D. McLeod, and P.S. Jensen (2007). Stigmatizing attitudes and beliefs about treatment and psychiatric medications for children with mental illness. Psychiatric Services, 58, 613-618.

Pescosolido, B.A., Monahan, J., Link, B.G., Stueve, A., \& Kikuzawa, S. (1999). The public's view of the competence, dangerousness, and need for legal coercion of persons with mental health problems. American Journal of Public Health, 89, 1339-1345.

Petrila, J. (2008). Because they do horrible things: Fear, science, and the erosion of civil liberties in sexually violent predator proceedings. Journal of Psychiatry \& Law, 36, 359-387.

Petrila, J. (2009). Congress restores the Americans with Disabilities Act to its original intent. Psychiatric Services, 60, 878-879.

Petrila, J., \& Christy, A. (2008). Florida's outpatient commitment law: A lesson in failed reform? Psychiatric Services, 59, 21-23.

PEW Center on the States. (2009). 1 in 31: The long reach of American Corrections. Retrieved fromhttp://www.pewcenteronthestates.org/uploadedFiles/PSPP_1in31_report_FINAL_W EB_3-26-09.pdf.

Poythress, N., Petrila, J., McGaha, A., and Boothroyd, R. (2002). Perceived coercion and procedural justice in the Broward County Mental Health Court. International Journal of Law and Psychiatry, 25, 517-533.

President's Commission on Mental Health (1978). Report to the President from the President's Commission on Mental Health, Volume 1. Washington DC: United States Government Printing Office. 
Prince, M., Patel, V., Saxena,S., Maj, Maselko, J., Phillips, M.R., \& Rahman, A. (2007). No health without mental health. The Lancet, 370, 859-877.

Raines, J.B., \& Laws, G. T. (2009). Mental health court survey. Criminal Law Bulletin, $45,4$.

Redlich, A. (2005). Voluntary, but knowing and intelligent: Comprehension in mental health courts. Psychology, Public Policy, and the Law, 11, 605-619.

Richards, E.P, Burris, S., McNelis, R.P., \& Hargan, E. (2005). Quarantine laws and public health realities. Journal of Law Medicine \& Ethics, 33, 69-

Ridgely, M.S., Borum, R., \& Petrila, J. (2001). The Effectiveness of Involuntary Outpatient Treatment: Empirical Evidence and the Experience of Eight States. Santa Monica: RAND.

Ridgely, M.S., Engberg, J., Greenberg, M. D., Turner, S., DeMartini, C., Dembosky, J.W. (2007). Justice, treatment, and cost: An evaluation of the fiscal impact of Allegheny County Mental Health Court. Santa Monica: RAND.

Ridgely, M.S., Engberg, J., Greenberg, M.D., Turner, S., DeMartini, C., Dembosky, J.W. (2007). Justice, treatment, and cost: An evaluation of the fiscal impact of Allegheny County Mental Health Court. Santa Monica: RAND.

Robbins, P.C., Callahan, L., \& Monahan, J. (2009). Perceived coercion to treatment and housing satisfaction in housing-first and supportive housing programs. Psychiatric Services, 60, 1251-1253.

Robbins, P.C., Petrila, J., LeMelle, S., \& Monahan, J. (2006). The use of housing as leverage to increase adherence to psychiatric treatment in the community. Adminstration and Policy in Mental Health and Mental Health Services Research, 33, 222-236.

Rosenbach, M.L., Lake, T.K., Williams, S.R., \& Buck, J.A. (2009). Implementation of mental health parity: Lessons from California. Psychiatric Services, 60, 1589-1594.

Rosenbaum, S., \& Teitelbaum, J. (2004). Olmstead at Five: Assessing the Impact. Kaiser Commission on Medicaid and the Uninsured. Retrieved from http://www.kff.org/medicaid/upload/Olmstead-at-Five-Assessing-the-Impact.pdf/

Salzter, M. S., Kaplan, K., \& Atay, J. (2006). State psychiatric hospital census after the 1999 Olmstead decision: Evidence of decelerating deinstitutionalization. Psychiatric Services, 57, 1501-1504.

Sartorius, N. (2007). Stigma and mental health. The Lancet, 370, 810-811.

Mental Illness, Law, and a Public Health Law Research Agenda 
Schulz, A.J., Williams, D.R., Israel, B.A., Lempert, L.B. (2002). Racial and spatial relations as social determinants of health in Detroit. Milbank Quarterly, 80, 677-707.

Schuurman, N., Bell, N., Hameed, S.M., \& Simons, R. (2008). The spatial epidemiology of trauma: the potential of GIS to organize data and reveal patterns of injury and services. Canadian Journal of Surgery, 51, 389-395.

Seeskin, K. (2008). Plato and the origin of mental health. International Journal of Law and Psychiatry, 31, 487-494.

Shern, D. (2007). Armed and dangerous: Law bans sale of firearms to people with a history of severe mental illness. http://www.cbsnews.com/stories/2007/04/27/60minutes/main2735294.shtml) accessed December 29, 2009 by JP.

Skeem, J., Eno Louden, J., Manchak, S., Vidal, S., \& Haddad, E. (2009). Social networks and social control of probationers with co-occurring mental and substance abuse problems. Law and Human Behavior, 33, 122-135.

Skeem, J., Manchak, S., \& Peterson, J.K. (2010). Correctional policy for offenders with mental illness: Creating a new paradigm for recidivism reduction. Law \& Human Behavior, in press. DOI 10.1007/s10979-010-9223-7

Skeem, J., \& Manchak, S. (2008). Back to the future: From Klockars' model of effective supervision to evidence-based practice in probation. International Journal of Offender Rehabilitation, 47, 220-247.

Skeem, J., Eno Louden, J., Polasheck, \& Cap, J. (2007). Relationship quality in mandated treatment: Blending care with control. Psychological Assessment, 19, 397-410.

Slinger, E., \& Roesch, R. (2010). Problem-solving courts in Canada: A review and a call for empirically-based evaluation methods. International Journal of Law and Psychiatry, in press, on-line at http://www.sciencedirect.com/science?_ob=ArticleURL\&_udi=B6V7W50K53S6-

$1 \&$ user $=2139826 \&$ coverDate $=07 / 20 / 2010 \&$ rdoc $=1 \&$ fmt $=$ high $\&$ orig $=$ search $\&$ ori gin $=$ search \&_sort $=\mathrm{d} \&$ docanchor $=\&$ view $=\mathrm{c} \&$ searchStrId $=1449984239 \&$ rerunOrigin $=$ google \&_acct $=$ C000054278\&_version $=1 \&$ urlVersion $=0 \&$ userid=2139826\&md5=8c9 dfd738a6582b2901f1f735a8d43a2\&searchtype $=\mathrm{a}$

Smith, J.D.E., \& Calandrillo, S.P. (2001). Forward to fundamental alteration: Addressing ADA Title II integration lawsuits after Olmstead v. L.C. Harvard Journal of Law and Public Policy, 24, 695.

Srebnik, D., \& LaFond J. (1999). Advance directives for mental health services: current perspectives and future directions. Psychiatric Services, 50, 919-925.

Mental Illness, Law, and a Public Health Law Research Agenda 
Srebnik, D., Russo, J., Sage, J., Peto, T., \& Zick, E. (2003). Interest in psychiatric advance directives among high users of crisis services and hospitalization. Psychiatric Services, 54, 981-986.

Steadman, H.J., Osher, F., Robbins, P., Case, B., \& Samuels, S. (2009). Prevalence of serious mental illnesses among jail inmates. Psychiatric Services, 60, 761-765.

Steadman, H., Mulvey, E., Monahan, J., Robbins, P., Appelbaum, P., Grisso, T., Roth, L., \& Silver, E. (1998). Violence by people discharged from acute psychiatric inpatient facilities and by others in the same neighborhoods. Archives of General Psychiatry, 55, 393-401.

Swanson, J.W. (1994). Mental disorder, substance abuse, and community violence: An epidemiological approach. In Monahan J and Steadman H (Eds.), Violence and Mental Disorder. Chicago: University of Chicago Press, 101-136.

Swanson J.W., Borum W.R., Swartz M.S., Hiday V.A., Wagner H.R., \& Burns B.J. (2001). Can involuntary outpatient commitment reduce arrests among persons with severe mental illness? Criminal Justice and Behavior, 28 (2):156-189.

Swanson J.W, Swartz M.S, Elbogen E., Wagner H.R, \& Burns B.J. (2003). Effects of involuntary outpatient commitment on subjective quality of life in persons with severe mental illness. Behavioral Sciences and the Law, 21, 473-491.

Swartz, M., Swanson, J., Steadman, H., Robbins, P., \& Monahan, J. (2009). New York State assisted outpatient treatment program evaluation. Duke University School of Medicine. Durham, North Carolina.

Swanson, J.W., Holzer, C.E. 3rd, Ganju, V.K., Jono, R.T. (1990). Violence and psychiatric disorder in the community: evidence from the Epidemiologic Catchment Area surveys. Hospital and Community Psychiatry 41, 761-70.

Swanson, J.W., Burris, S., Moss, K., Ullman, M.A., \& Ranney, L.M. (2007). Justice Disparities: Does the ADA enforcement system treat persons with psychiatric disabilities fairly? Maryland Law Review, 7(66), 94-139.

Swanson, J., Swartz, M., Van Dorn, R., Elbogen, E., Wagner, H., Rosenheck, R., Stroup, T., McEvoy, J., \& Lieberman, J. (2006). A national study of violent behavior in persons with schizophrenia. Archives of General Psychiatry, 63, 490-499.

Swanson J.W., Swartz M.S., Borum R.B., Hiday V.A., Wagner H.R., \& Burns B.J. (2000). Involuntary out-patient commitment and reduction of violent behaviour in persons with severe mental illness. British Journal of Psychiatry, 176, 324-331.

Swartz M.S., Swanson J.W., Wagner H.R., Burns B.J, Hiday V.A., \& Borum W.R. (1999). Can

Mental Illness, Law, and a Public Health Law Research Agenda 
involuntary outpatient commitment reduce hospital recidivism? Findings from a randomized trial in severely mentally ill individuals. American Journal of Psychiatry, 156(12), 1968-1975.

Swanson, J.W., Swartz, M.S., Essock, S.M., Osher, F.C., Wagner, H.R., Goodman, L.A., Rosenberg, S.D., Meador, K.G. (2002). The social-environmental context of violent behavior in persons treated for severe mental illness. American Journal of Public Health, 92(9): 1523-1531.

Swanson, J. W., Swartz, M. S., Ferron, J., Elbogen, E. B., \& Van Dorn, R. A. (2006). Psychiatric advance directives among public mental health consumers in five United States cities: Prevalence, demand, and correlates. Journal of American Academy of Psychiatry and the Law, 34(1), 43-57.

Swanson, J.W., Van Dorn, R.A., Swartz, M.S., Smith, A., Elbogen, E.B., Monahan, J. (2008). Alternative pathways to violence in persons with schizophrenia: the role of childhood antisocial behavior problems. Law Hum Behav.32(3):228-40.

Szasz T. (1998). Thomas Szasz's Summary Statement and Manifesto. http://www.szasz.com/manifesto.html.

Teplin, L.A., Abram, K.M., McClelland, G.M., \& Dulcan, M.K. (2002). Psychiatric disorders in youth in juvenile detention. Archives of General Psychiatry, 59, 1133-1143.

The President's New Freedom Commission on Mental Health (2003). Achieving the Promise: Transforming Mental Health Care in America. Final Report. Washington DC.

Tornblom, K., Vermunt, R. (2007). Distributive and Procedural Justice: Research and Social Applications. Burlington VT: Ashgate Publishing Company.

Torrey, E.F. (1997). Out of the shadows: Confronting America's mental illness crisis. New York, NY: John Wiley.

Torrey, E.F., \& Zdanowicz, J. D. (2001). Outpatient commitment: What, why, and for whom. Psychiatric Services, 52, 337-341.

Tuke, S. (2009/1813). Description of the retreat: An Institution near York, for insane persons of the Society of Friends. Charleston, SC: BiblioLife.

Tyler, T. (2005). Procedural Justice: Volume 1. Burlington VT: Ashgate Publishing Company.

Van Dorn, R.A., Swartz, M.S., Elbogen, E.B., Swanson, J.W., Kim, M., Ferron, J., Scheyett, A.M. (2006). Clinicians' attitudes regarding barriers to the implementation of Psychiatric Advance Directives. Administration and Policy in Mental Health and Mental Health Services, 33(4), 449-60.

Mental Illness, Law, and a Public Health Law Research Agenda 
Weisbrod, B.A., Handler, J.F., \& Komesar, N.K. (1978). Public Interest Law: An Economic and Institutional Analysis. Berkeley and Los Angeles, CA: University of California Press.

Wertheimer, A. (1990). Coercion (Studies in Moral, Political and Legal Philosophy). Princeton: Princeton University Press.

Williams, S.M., Chapman, D., \& Lando, J. (2005). The role of public health in mental health promotion. Morbidity and Mortality Weekly Report, 54, 841-842.

Winick, B.J. (1996). Advance directive instruments for those with mental illness. University of Miami Law Review, 51 (1), 57-95

Wintermute, G.J. (2008). Guns, fear, the Constitution, and the public's health. New England Journal Of Medicine, 358, 1421-1424.

World Health Organization (2008). mhGAP. Mental Health Gap Action Programme. Scaling Up Care for Mental, Neurological, and Substance Use Disorders. Geneva: World Health Organization. 